idlentification. The fragment indicated that the patient had been drinking lemonade, as it was the pulp vesicle of a lemon, and a telegram to this effect was sent the physician. Similar cases are by no means uncommon.

The coroner's jury found that the deceased in the present case came to his death from poisoning due to male-fern procured from a certain person known as the "Indian doctor" of Joplin, Mo. The striking features of the case are, first, that the patient probably had no tapeworm and so met his death partly as the result of stupidity of diagnosis, and second, that the "doctor" should send a poison as powerful as oleoresin of male-fern, evidently in amounts in excess of the ustral dose, to be administered to a person in another state, and further to order that the male-fern be followed by castor oil, a procedure known to increase the absorption and toxicity of the drug, the patient's death in consequence being directly due to extraordinary stupidity in treatment. There is always the evident possibility that such persons as this "Indian doctor" will cause the death of the person who trusts their preparations; it is worth while to put concrete cases of the sort on record as an aid to those who would keep others out of danger.

\section{SHOTGUN WOUND OF ABDOMEN, WITH RUPTURE OF PREGNANT UTERUS}

\section{Lincoln Davis, M.D., Boston}

Assistant Visiting Surgeon, Massachusetts General Hospital

Paticnt.-F. F. (No. 193531), an Italian woman, aged 36, married, housewife, was brought to the Accident Department of the Massachusetts General Hospital, Jan. 25, 1914, at $7: 45$ p. m., by the police ambulance of a neighboring town. No history was obtainable from the patient on account of her unfamiliarity with the English language and her condition of shock. It was said that she had been shot with a shotgun at close range about thirty minutes before entrance.

Physical Examination.-A well-developed and well-nourished woman in considerable shock, moaning, but conscious. Skin somewhat clammy; mucous membrane pale; pupils equal, regular and reacting normally. Size and position of heart normal; sounds regular and of fair quality; no murmurs heard. Lungs clear and resonant throughout both fronts, backs not examined. Abdomen somewhat distended, with an irregular, lacerated wound in the lower half, the larger portion of which was in the right lower quadrant. The wound was very irregular in outline, with much laceration and shredding of the tissues of the abdominal wall; its longest diameter was transverse, and it was of a size to aclmit two fists into the abdominal cavity. Protruding from it were two or three coils of the small intestine, approximately about 3 or 4 feet in length. A portion of the bowel lay in contact with the table when the patient was first seen. Blood oozed freely from the wound. In the right groin, about 2 inches below Poupart's ligament, were two small punctured wounds about $2 \mathrm{~mm}$. in diameter, with slightly irregular and infolded edges. No powder burns were seen. No wounds of exit could be recognized. Left leg and foot were moderately swollen, pitting on pressure and apparently associated with numerous varicosities of veins and venules in the lower leg and foot. A pelvic examination was not made. There was no bleeding from vulva. Knee-jerks were equal and active. Temperature 98.6. Pulse 63.

Sterile towels, wet with hot salt solution, were immediately applied to abdomen to cover intestines. Morphin sulphate, $1 / 4$ grain, and camphorated oil, 30 minims, were given intramuscularly and 1 pint of normal salt solution was injected under the right breast. Preparations were made for an immediate operation.

Operation,-Ether anesthesia. Moist sterile towels were placed over the protruding intestines, and the skin of the abdominal wall prepared with benzin, iodin and alcohol. Examination of protruding bowel revealed about forty small perforations scattered along from 2 to 3 feet of the bowel, and in some places shot could be palpated in the bowel wall. Gas and a slight amount of frothy fecal matter exuded from some of the perforations. The perforations were infolded with purse-string sutures of silk, several being included in one suture in many instances. At one point this infolding caused a marked constriction of the lumen of the intestine, but gas could be squeezed through. The intestines were carefully washed with warm salt solution and replaced. There was considerable hemorrhage in the abdominal cavity. Exploration showed an enlarged uterus with a rent in the anterior wall about 4 inches long. An umbilical cord protruding from the wound in the utertus led to a fetus, estimated at about four months, which was lying loose in the abdominal cavity. The placenta was removed from the uterus manually, and the uterine wall closed with No. 2 interrupted chromic catgut sutures. The patient was given one ampule of sterile ergot subcutaneously. No other intra-abdominal injury was found. The abdominal cavity was irrigated with warm saline solution. One cigaret-wick was placed to the right iliac fossa and one to the pelvis. The fascia, muscle and peritoneum of the abdominal wall were closed in a transverse direction in one layer with No. 2 interrupted chromic catgut, after the lacerated edges of fascia and skin had been trimmed away. The skin $v$ as loosely approximated with interrupted silkworm-gut, with two cigaret-drains to the subcutaneous tissue. Patient's pulse at the end of operation was 84. She was sent to the ward in surprisingly good condition and placed in Fowler's position, with rectal saline seepage.

Posloperative History.-The patient made a steady and uneventful convalescence. There was some sloughing of the edges of the wound with separation of the skin. This was later closed by secondary suture, with local anesthesia. A few stray shot were removed from the superficial layers of the abdominal wall and groin. These corresponded to about No. 7 bird-shot. March 10, 1914, the patient was discharged to the Convalescent Home in excellent general condition with a very small granulating wound. Two weeks later she was discharged from the Convalescent Home, the wound being entirely healed and solid, without evidence of hernia. She was in excellent general health and was able to walk about and upstairs without difficulty. Bowels moved normally, and the uterus had undergone normal involution.

Remarks.-An interesting point in this case was that while the direction of the wound in the abdominal wall was distinctly transverse, the uterus was ruptured in a longitudinal direction and no marks or shot wounds of any kind could be found on the body of the fetus. It would seem that the rupture of the uterus was the result of a bursting strain rather than of actual perforation by the shot. The withstanding of a very considerable loss of blood without particular evidence of shock may be accounted for by the pregnant condition of the patient.

205 Beacon Street.

Salvarsanized Serotherapy.-Bériel and Durand emphasize that if the serum is drawn soon after the salvarsan has been given and is then injected into another person, this is not serotherapy but chemotherapy, as more or less of the drug is still in the serum and there has been time enough for the antibodies to be generated in response to the action of the drug. In their clinical work in this line they always allow two or three days to elapse before drawing the serum for therapeutic use on another patient. In their communication in the Bulletins ct ménoircs de la Société medicale des hôpitant. de Paris, they relate their experiences in this line with intraspinal injection of serum from persons who were just entering on the second stage of salvarsan two or three days before. They keep the serum for twenty or forty-eight hours, heat it to $56 \mathrm{C} .(132.8 \mathrm{~F}$.) and then make the intraspinal injection in cases of tabes or paresis. They report encouraging results to date. 